\title{
Blame the technocentric artefact! What research tells us about problems inhibiting teacher use of IT
}

\author{
Deryn M. Watson \\ School of Education \\ King's College London \\ Waterloo Road, London SE1 8WA, UK \\ Tele + 44171872 3106; Fax + 441718723182 \\ E-mail:deryn.watson@kcl.ac.uk
}

\begin{abstract}
Despite substantial resource provision and a number of national and regional strategies, the impact of IT in education is still relatively small. There is an apparent resistance by teachers to the use of IT within the normal pedagogy of the classroom. The confusion of purpose about the role of IT in schools is part of the problem. But more significantly teachers' reluctance is fueled by a complex intertwining of the technocentric focus associated with IT, real barriers to change and professional unease. The key to change, for both developed and developing countries, lies in addressing the concerns of teachers rather than imposing change upon them.
\end{abstract}

Keywords

Attitudes, case studies, developed countries, pedagogy, professional development

Most countries espouse the role and value of Information Technology (IT) in education. Issues such as redefining the curriculum, new styles of teaching, empowering individualized learning and moving beyond the idea of a fixed location school are often discussed as if both the ideas and the power of IT to deliver them are incontestable. Yet evidence from developed countries, who have been 'using IT in education' for a number of years, suggests that the relationship 
between IT and learning at all levels is complex and fragile. Indeed after so much resource provision, and so many national and regional strategies the impact is still relatively small. An examination of why is this so, with reference to research analysis and literature, may enable developing countries to avoid the same mistakes.

\section{THE CURRENT SITUATION}

Since 1973 the UK has been regularly promoting the use of computers in education through a number of national initiatives. There have been programmes for the purchase of hardware, the development of educational software and the training of teachers. A national agency has been in place for 15 years with the specific remit to promote the use of educational technology. Yet the recent independent McKinsey report (Stevenson,1997) stated:

'The UK has a higher ratio of computers per schoolchild than almost any other country, including the US. Yet despite this lead and the fact that information technology has been on the educational agenda for almost 30 years, it is not clear that IT has made a significant impact on educational standards.'

Pelgrum and Plomp (1991) reported in the IEA study, which covered 19 countries, that with the exception of the USA, only a small percentage of teachers in schools were actually using computers as part of their teaching. In the UK a series of government biennial statistics on the use of IT in schools has shown that despite a rise in the number of computers and a growing number of teachers reporting being confident with computers, the number who actually use them substantially in their teaching, rather than for administration or personal use, is still relatively small - at just under $10 \%$. The figure has been consistent for some years. The most notable change since 1989 has been the growth of educational administration and the use of computers to teach IT skills in separate lessons.

The reasons for the apparent resistance to the use of IT within the normal pedagogy of the classroom needs further exploration. Evidence from three recent research projects, ImpacT - An Evaluation of the Impact of Information Technology on Children's Achievements in Primary and Secondary Schools (Watson, 1993), PLAIT (Pupils' Learning and Access to Information Technology) (Gardner, et. al., 1992) and STAC (Supporting Technology across the Curriculum) (Ridgway and Passey, 1995) has shown that a number of factors appear to be involved. First the level and nature of IT depends upon resource provision, access and particular curriculum requirements. At the moment none of this infrastructure appears to support the majority of teachers and their current pedagogy in schools. Indeed all the projects focused on the role of the teacher, noting that the majority of teachers were unaware of or unwilling to explore the contribution which IT can make to their pupils' learning. It is clear that, as with other innovations, we need to focus on the role and perceptions of the teacher in order to understand why the take up of IT in education has been so resolutely disappointing. 
It is clear that one major factor has been the confusion of purpose about the role of IT in schools, and how best that might be addressed (Watson, 1997). Van Weert (1986) has defined four interrelated roles of IT use in education.

1. Learning about IT, including programming and systems design; i.e., IT as a separate subject;

2. Learning with the aid of IT, such as using a graphics calculator or CD-ROM, i.e., IT as a teaching resource;

3. Learning by means ofIT, such as using simulations and modeling, i.e., IT as an integral part of the learning;

4. IT to organize education, such as pupil records, i.e., IT for educational management.

The last role is not of concern in this paper. But the first three have, in both the UK and elsewhere, been the subject of much debate. There has been a tendency to promote first one and then the other. Thus schemes to promote first computer science and now IT as a separate subject have been perceived as separate from and not related to the role of IT as a learning resource. The use of IT tools as a resource sits uncomfortably in the middle. The fault lies in the conception that the three roles are somehow distinct from each other, resulting in a dichotomy of purpose between a vocational and pedagogic agenda. Few schools have been able to incorporate all three. OFSTED, the UK's national inspection agency, reported that pupils were often practising low level skills and there were often insufficient opportunities to apply the IT skills, learnt in separate IT classes, to work in other subjects. As Ragsdale (1988) has noted, knowledge of IT skills does not mean the skills are always applied. He indicates that acquiring IT tool skills may be relatively easy but gaining wisdom to use them effectively is not. In reality not many teachers are using computers in their classes.

Thus there has been a lack of integration, a perception that IT has different identities and purposes within the same educational establishment. The McKinsey report (Stevenson, 1997) reflects on the 'lack of clarity of objectives' and argues for a more integrated approach. It also states that 'we need to be clearer about what we want children to learn (with IT) and whether learning should be about acquiring vocational skills or about learning for its own sake'. The focus on IT skills solely for vocational purposes has contributed to the rejection by most teachers, for whom pedagogic purpose and implementation lie at the heart of their professional concerns.

Recent further analysis of my case study research undertaken as part of the ImpacT project provides some further understanding of this phenomenon. In five schools, only one geography teacher in each department used computers; those teachers also failed to influence their colleagues (1993). Focusing on the reluctance of the colleagues helps identify further causes for their rejection - a complex intertwining of the technocentric focus, real barriers to change and professional unease. 


\section{SYMBOLIC FUNCTION OF TECHNOLOGY}

Technology today appears to hold a major symbolic function in society, associated with imagery of the new, positive change and renewal, and of economic revival. From Logo to the Superhighway, education has been drawn into the confused notions of a technocentric society. As Bryson and de Castell (1994) state there are a wide range of policy documents that:

'... urge educators to grapple with the implications of an 'explosion in knowledge, coupled with powerful new communication and information processing technologies' and therefore promote widespread 'technological literacy'. Arguments that enthusiastically promote the widespread implementation of educational computing typically predict that these technologies will (1) facilitate teaching processes, and (2) promote significant positive gains, both academic and vocational, for students.'

Evaluation studies such as Cuban's (1986) suggest that unreflexive and unabashed optimism about the necessarily transformative nature of new educational technologies is both naive and historically unfounded. Indeed Miller and Olson (1994) consider that 'the history of innovation in education should teach us to be cautious about predictions associated with new technologies. However there is something about computers that seems to negate this caution'.

It is clear that the conception of technology as an artefact, a desirable innovation that 'ought to be used', is itself part of the problem. The teacher colleagues in my case study were resisting partly because they resented the assumption, the value assumption, that IT 'should be done'.

The culture of technocentric mindedness can result in curriculum programmes that produce an alienation because they are perceived to have attitudes hostile to teachers' pedagogic culture. My reluctant teachers resented the intrusion upon their geography curriculum of IT. A technocentric culture distorts knowledge by focusing on it as information. Many teachers do not recognize this as part of their professional environment and so articulate barriers to use. In all countries, whether defined as developed or developing, IT must be perceived as an integral rather than separate and new transformational part of the curriculum.

\section{BARRIERS TO CHANGE}

It is important to see the role of the new technology through the eyes of the uncommitted classroom teacher. My case study teachers' colleagues articulated a number of reasons for not emulating their colleagues' use of IT. The rare in-service they reported had all the hallmarks of the failures recorded by Fullan (1991), who stated that 'in-service education or ongoing staff development explicitly directed at change has failed in most cases because it is ad hoc, discontinuous, and unconnected to any plan for change'. While both formal and informal attempts to share experiences had occurred within their schools they were hampered by lack of time for regular and ongoing reflection. Many reported poor experiences when using software both in an in-service context and in their classes, which I believe reflected 
their lack of professional confidence in the role and use of the resource. This poor experience coloured their willingness to explore further, even when the means were close at hand.

Problems with access also featured large. For teachers in the ImpacT study the location and control issues of the resource were simply too cumbersome, and lacked the flexibility and spontaneity which they needed and had in their own geography classrooms. Andrews (1992) has reported from a survey among mathematics teachers ( 75 replies from 40 schools) that booking in advance guarantees access for only half the teachers and spontaneous access granted to only one in ten. Wellington (1988) reported from a large survey that the advent of computer networked suites reduced both the amount and range of subject CAL that took place in schools. Even so the regular access to computers available in the PLAIT project (Gardner, et. al., 1992) was found to be no guarantee that they would be used or the pupils' performance improved.

But questions of training, access and control were overshadowed by the problem of time - time to learn and explore, time to gain confidence and time to reflect on the potential for their pedagogy. This has been a common theme in the literature; teachers need time to reflect and consider the implications of the new. Drawing upon the longitudinal research project in Kingston Ontario, Olson (1995) raised the problem that teachers are not provided with enough time to reflect on practice and change. Indeed he believed teachers appear to be expected to take substantial risk in accommodating IT in their teaching that threatens their classroom ethos. He noted the value of computers in that they may help teachers to confront their experience; change is not just adoption and integration of the technology but involves personal reflection and adaptation as well.

Bliss, Cox and Chandra (1986) concluded from a study in one school that although the general attitude of staff towards computers was positive more than half had misgivings. They felt the change in their role occasioned by computers was unfavourable and they perceived their traditional role was threatened. Ridgeway and Passey (1995) considered that the advocates of computers, through overambitious claims and an underestimation of practical constraints, seed failure; computers challenged teachers' fundamental values and practices. Teachers have identified barriers as lack of full access to computers, lack of personal preparedness and the problem of unanticipated negative consequences of computer use. It appears that teachers in schools are less favourably inclined towards computers because they feel incompetent, because the facilities available are inadequate or because they are not yet convinced of their educational potential.

The large IEA international survey (Pelgrum and Plomp, 1991) confirmed that lists of barriers quoted by teachers consistently included difficulty of access and lack of time. I believe these barriers can be seen as the manifestation of a vicious circle in which these teachers feel trapped, unable to see a way forward or negotiate a route for exploring and adopting regular computer use in their classrooms. I believe that teachers used their articulation of time as a barrier in part to justify and reflect their overall unease with the innovation.

Many of the barriers to the adoption of computers in schools are simply specific examples of barriers to change in general. Willis (1993) in particular identifies a number of barriers common to all change but which may have a particular resonance for why 'efforts that involve technology may be particularly difficult to 
pull off'. The Williams and Williams (1994) study is based on the notion that the greater the number of conditions that are positive in any one scenario, the greater the chance of success. However identifying barriers to change still places the focus on the innovation as a construct, an artefact with characteristics teachers, in many different environments, have difficulty in accepting.

DEFICIT MODEL OF TEACHERS

One effect of this has been to maintain the long-standing association of the teacher as failure, the deficit model. Willis (1992) asks 'why do some teachers, when faced with an opportunity to begin using technology in their classroom, treat it more like a disease to be avoided than a promising aid to effective instruction?' His language indicates inadequacies of teachers rather than the innovation; he relates the inadequacies to whether teachers have Arts- or Science-based backgrounds. The PLAIT report, an evaluation of the use of laptops (Gardner, et. al., 1992), was concerned to find that curriculum requirements alone do not sustain daily use. Laptops were distributed to all pupils; their relatively sparse use was attributed to:

'... the inability of the wider teaching community to stimulate and extend the frequency of computer usage in the classroom. Indeed usage in some cases may not be frequent at all. Teachers are not felt to be sufficiently IT literate to easily and effectively integrate IT into their teaching. .... It is therefore unlikely that the frequency of usage will be greatly extended by innovations in teaching methods until teachers themselves are as literate in IT techniques as the pupils are expected to become'.

At no stage do the PLAIT evaluators address the possibility that the barriers perceived by the teachers may be sensible ones. As advocates of the technology they assume the artefact is desirable. PLAIT teachers were only offered three general purpose packages - word processing, data handling and spreadsheets - on the laptops. No indication is given of how frequently the use of such packages might fit into the subject curriculum concerns of the teachers. Ostlund (1974) highlighted the idea that attention must be placed on the characteristics of the innovation characteristics such as relative advantage, compatibility with existing procedures, trialability, reversibility and risk. He noted that the same innovation does not have the same characteristics for all disciplines. So much of the advocacy of the use of computers in education has come from 'outside' agencies or national projects. Their stake in the technology could be said to have blinkered their analysis of such issues as compatibility, reversibility and risk that teachers in schools have faced. It is perfectly logical and sensible for teachers, when pressed for time in a busy schedule, to revert for the sake of efficiency, to routines and resources they feel comfortable with.

\section{FOCUS ON PROFESSIONAL CONCERNS OF TEACHERS}

The separation of the innovation from the classroom teacher and the idea that the teacher is at fault - that the teacher is an empty vessel into which this externally 
defined innovation must be poured - these notions have produced failure. Such perceptions focus on the innovation itself and in this focus its definition increasingly isolates it from the teaching and learning environment by locating it as something different and outside, an alienating artefact, that must now be brought within. The rhetoric to introduce Information Technology in schools has all the hallmarks of an imposed, mechanistic, top-down model of change, with a particular focus on the nature of technology within a wider national economic agenda. Many teachers have responded by articulating a number of barriers to using computers.

Excessive attention to the acquisition of hardware, a technocentric imperative that placed the desirability of the technology above its educational purpose and a confusion of how this should be translated into real IT use in the curriculum, have contributed to failure of substantial adoptions in developed countries. Thus the route taken by many developed countries so far would be a poor role model for developing countries. More attention is needed to consistent and appropriate pedagogic use with an infrastructure for support that includes ease of access and time to incorporate IT into a well-established curriculum. Time for teachers to reflect professionally is essential. Strategies targeting professional capacity building will have a greater chance of success. They need to be focused not on the technology but on pedagogy and on the delivery mechanisms to be contexted within, rather than superimposed on, the real professional environment of the teacher.

Andrews, P. (1992) Teachers' perceptions of the availability of computer hardware. Journal of Computer Assisted Learning, 11(2), 90-98.

Bliss, J., Chandra, P., \& Cox, M. J. (1986) The introduction of computers into a school. Computers and Education, 10, 49-54.

Bryson, M. and de Castell, S. (1994) Telling tales out of school: modernist, critical and postmodern 'true stories' about educational computing. Journal of Educational Computing Research, 10(3), 199-221.

Cuban, L. (1986) Teachers and Machines: The Classroom Use of Technology Since 1920. Teachers College Press, New York.

Fullan, M. (1991) The New Meaning of Educational Change. (Second edition). Cassell, London.

Fullan, M. and Hargreaves, A. (eds.) (1992) Teacher Development and Educational Change. Falmer Press, London.

Gardner, J., Morrison, H., Jarman, R., Reilly, C., and McNally, H. (1992) Pupils' Learning and Access to Information Technology: An Evaluation. School of Education, The Queens University of Belfast, Belfast.

Stevenson, D. (1997) The Future of Information Technology in UK Schools. McKinsey and Company, London.

Miller, L., \& Olson, J. (1994) Putting the computer in its place: a study of teaching with technology. Journal of Curriculum Studies, 26(2), 121-141.

Olson, J. (1995) Classroom ethos and the concerns of the teacher, in Integrating Information Technology into Education. (eds. D. M. Watson and D. Tinsley), Chapman \& Hall, London. 
Olson, J. (1995) Classroom ethos and the concerns of the teacher, in Integrating Information Technology into Education. (eds. D. M. Watson and D. Tinsley), Chapman \& Hall, London.

Ostlund, L. (1974) Perceived innovation attributes as predictors of innovatedness. Journal of Consumer Research, 1, 23-29.

Pelgrum, W.J. and Plomp, T. (1991) The Use of Computers in Education Worldwide. Pergamon Press, Oxford.

Ragsdale, R. (1988) Permissable Computing in Education: Values, Assumptions and Needs. Prager, New York.

Ridgway, J., \& Passey, D. (1995) Usin g evidence about teacher development to plan systemic revolution, in Integrating Information Technology into Education. (eds. D. M. Watson \& D. Tinsley), Chapman \& Hall, London.

van Weert, T (1986) A model syllabus for literacy in information technology for all teachers, in Information Technology and Education: The Changing School (eds. R Ennals, R. Gwyn and A. Zdravchev), Ellis Horwood, London.

Watson, D.M. (Ed.). (1993). The ImpacT Report: An Evaluation of the Impact of Information Technology on Children's Achievements in Primary and Secondary Schools. Kings College London, London..

Watson, D.M. (1993) Do enthusiastic users inhibit change?, in Informatics and Changes in Learning. (eds. D. C. Johnson and B. Samways), North Holland, Amsterdam.

Watson, D.M. (1997) A dichotomy of purpose: The effect on teachers of government initiatives in IT, in Information Technology: Supporting Change through Teacher Education (eds. D. Passey and B. Samways), Chapman \& Hall, London.

Wellington, J.J. (1988) Computer education in secondary schools: an electronic survey. Journal of Computer Assisted Learning, 4(1), 22-33.

Williams, J.C. and Williams, J.B. (1994) Change at the chalk face: A case study of the factors affecting the adoption of curriculum innovation. Journal of Curriculum Studies, 26(2), 201-216.

Willis, J. (1992) Technology diffusion in the 'soft disciplines': Using social technology to support Information Technology. Computers in the Schools, 9(1), 81-118.

9

\section{BIOGRAPHY}

Deryn Watson is a Senior Lecturer in Educational Computing at King's College London. Since the mid-1970s she has been actively involved in the research and development of CAL materials in the humanities and languages, writing both on models of software development of CAL materials and the potential for interactive learning. She has conducted research into the effects of the location of computers and the impact of IT on children's learning. Her current research is on the role of ICT in teacher education, an examination of IT national policies and the reality of IT use in schools. 